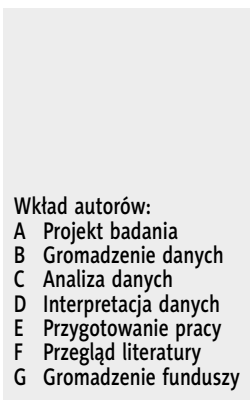

\section{Zasada cross-check w diagnostyce narządu słuchu}

\section{Chross-check principle in hearing diagnostics}

\author{
Edyta Piłka ${ }^{A B C D E F}$
}

Instytut Fizjologii i Patologii Słuchu, Światowe Centrum Słuchu, Zakład Audiologii Eksperymentalnej, Warszawa/Kajetany

\title{
Streszczenie
}

W roku 1976 Jerger i Hayes, mając na uwadze to, że wyniki badań behawioralnych cechuje mała wiarygodność, opracowali protokół zasady cross-check, której istotą było potwierdzanie wyników badań behawioralnych badaniami obiektywnymi.

W pracy zaprezentowano dwa przypadki osób dorosłych, u których zastosowanie zasady krzyżowej miało niebagatelny wpływ na wynik końcowy diagnostyki narządu słuchu. Udowodniono, iż bez względu na wiek pacjenta na proces leczenia ma wpływ nie tylko odpowiednia technika pomiarowa, stosowanie właściwych zasad czy dobra współpraca ze strony osoby badanej, lecz także ważna jest weryfikacja otrzymywanych wyników za pomocą innych testów obiektywnych i subiektywnych.

Słowa kluczowe: zasada cross-check, zasada krzyżowa, diagnostyka słuchu

\begin{abstract}
Taking into consideration a low reliability of behavioral studies, in 1976 Jerger and Hayes have introduced a cross-check principle, which consists in confirming the results of behavioral tests with objective tests.

In this paper we present two cases of adult patients in whom the application of a cross-check principle had a significant impact on the final effect of the diagnostic process of a hearing organ. It demonstrates that, regardless of patient's age, apart from a choice of an appropriate measurement technique, the application of proper principles, or good cooperation with the person being tested, what is equally important in the process of treatment is also the verification of the results by performing other objective and subjective tests. Key words: cross-check principle, hearing diagnostics
\end{abstract}

\section{Wprowadzenie}

W roku 1976 Jerger i Hayes, mając na uwadze to, że wyniki badań behawioralnych cechuje mała wiarygodność, szczególnie w populacji dziecięcej, opracowali protokół zasady cross-check (pol. zasada krzyżowa). Zasada ta polegała na tym, że wyniki badań behawioralnych potwierdzane były badaniami obiektywnymi, takimi jak audiometria impedancyjna czy potencjały wywołane pnia mózgu (ang. Auditory Brainstem Response, ABR) [1]. Protokół obrazujący działanie tej zasady został przedstawiony na rycinie 1 .

Jak pokazują badania, dzięki stosowaniu zasady krzyżowej wzrasta dokładność diagnostyki audiologicznej $[2,3]$, której zadaniem jest nie tylko określenie stopnia utraty słuchu czy typu uszkodzenia, lecz także umożliwienie zlokalizowania na drodze słuchowej miejsca, w którym wystąpiła patologia $[4,5]$. W literaturze przedmiotu często

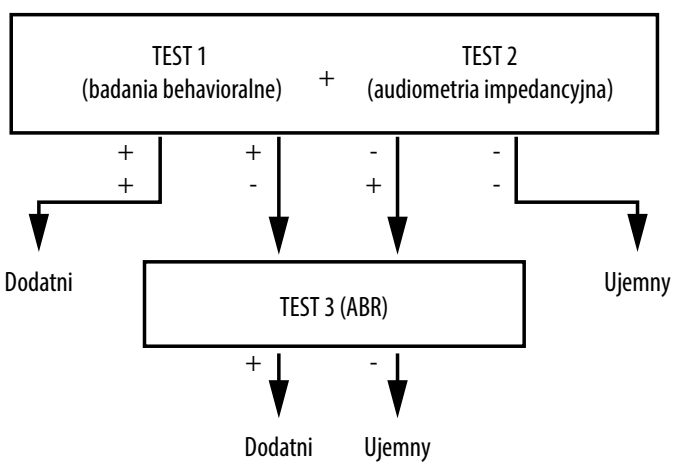

Rycina 1. Protokół zasady cross-check zaproponowany przez Jergera i Hayesa w 1976 roku

Figure 1. Cross-check principle protocol proposed by Jerger and Hayes in 1976

Adres autora: Edyta Piłka, Światowe Centrum Słuchu, Zakład Audiologii Eksperymentalnej, ul. Mokra 17, Kajetany, 05-830 Nadarzyn, e-mail: e.pilka@ifps.org.pl 
podkreślany jest fakt, iż w przypadku szacowania głębokości ubytku słuchu w pierwszej kolejności powinny być wykonywane podstawowe badania audiometryczne. Jednakże znaczącym uzupełnieniem może być wówczas zastosowanie obiektywnych metod badawczych [6-8] czy prób stroikowych $[9,10]$. Kochanek, w swojej pracy dotyczącej zastosowania ABR w diagnostyce zaburzeń słuchu u małych dzieci, zwraca uwagę na to, że każde z badań audiologicznych ocenia inny odcinek drogi słuchowej [11]. Podkreśla tym samym istotność weryfikowania wyników badań otrzymanych metodami obiektywnymi, dzięki którym oceniany jest stan ucha środkowego czy próg słyszenia, ale nie procesy percepcji i analizy słuchowej.

\section{Cel pracy}

Celem pracy jest pokazanie, jak istotne jest stosowanie zasady cross-check w diagnostyce narządu słuchu.

\section{Materiał i metoda}

Wykorzystanie zasady krzyżowej w praktyce audiologicznej przedstawiono na przykładzie dwojga pacjentów leczonych w Instytucie Fizjologii i Patologii Słuchu (IFPS).

\section{Przykład 1 - Pacjent A}

42-letni mężczyzna zgłosił się do IFPS ze skierowaniem na obustronne leczenie operacyjne. Jakościowa ocena audiogramu, wykonanego w miejscu zamieszkania, wykazała lewostronny niedosłuch przewodzeniowy oraz niedosłuch mieszany po stronie prawej (rycina 2).

W wypisie z poradni otolaryngologicznej zawarta była informacja o przebytych operacjach w uchu prawym i próbie aparatowania tego ucha metodami klasycznymi. Jednakże z uwagi na liczne wycieki i brak poprawy rozumienia mowy, odstąpiono od doboru aparatu.
Na pierwszej wizycie w IFPS u mężczyzny wykonano próby stroikowe Webera i Rinnego, audiometrię tonalną i impedancyjną oraz audiometrię słowną.

\section{Przykład 2 - Pacjent B}

Pacjentka, lat 25, zgłosiła się do Kliniki Szumów Usznych IFPS. Wcześniej z powodu odczuwania szumów usznych leczona była w kilku poradniach otolaryngologicznych, w których na podstawie badań przedmiotowych oraz progowego badania słuchu nie stwierdzano odchyleń od stanu prawidłowego.

W czasie wywiadu przeprowadzonego w IFPS kobieta zaznaczyła, że szumy uszne pojawiają się u niej okresowo, w momencie uczucia zatkania i pełności w uszach. Wówczas swój głos słyszy nienaturalnie - „jak ze studni”.

U Pacjentki B wykonano audiometrię tonalną, słowną i impedancyjną, ABR (diagnostykę różnicową), emisję produktów zniekształceń nieliniowych (ang. Distortion Product Otoacoustic Emissions, DPOAE) oraz test drożności trąbek słuchowych (ang. Eustachian Tube Function Test, ETFT) $\mathrm{z}$ wykorzystaniem testu Williams.

\section{Wyniki}

Pierwszym badaniem wykonanym w IFPS u Pacjenta A była próba Webera. W czasie jej przeprowadzania przy użyciu przetwornika kostnego mężczyzna wskazywał lateralizację dźwięku do ucha lewego. Następnie wykonano próbę Rinnego z wykorzystaniem stroika C2 - $512 \mathrm{~Hz}$. W trakcie wykonywania testu zagłuszano ucho niebadane poprzez rytmiczne naciskanie skrawka tego ucha (metoda Wagnera). Po stronie lewej czas słyszenia wzbudzonego stroika poprzez przewodnictwo powietrzne był krótszy niż słyszenia kostnego (Rinne ujemny), natomiast po stronie prawej pacjent nie słyszał stroika ani drogą kostną, ani powietrzną.
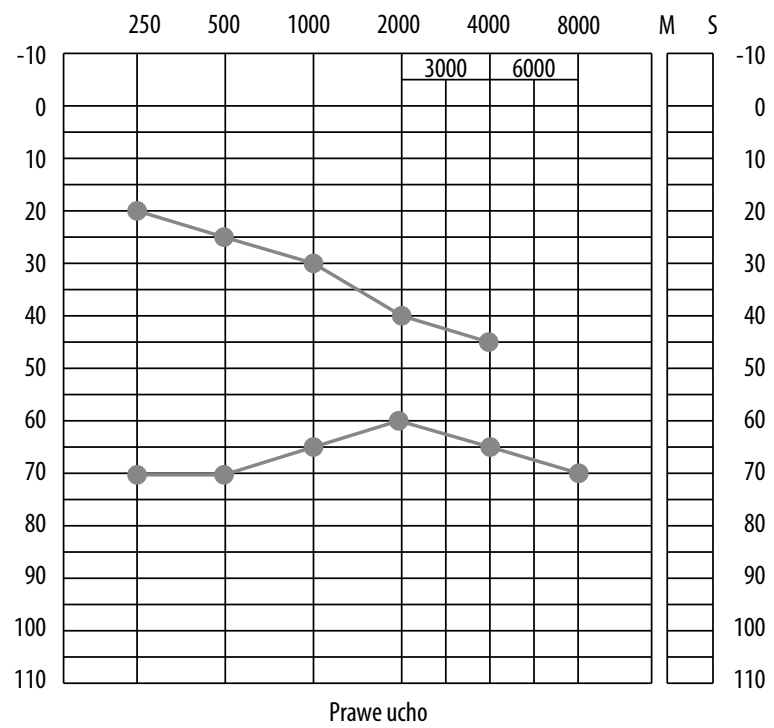
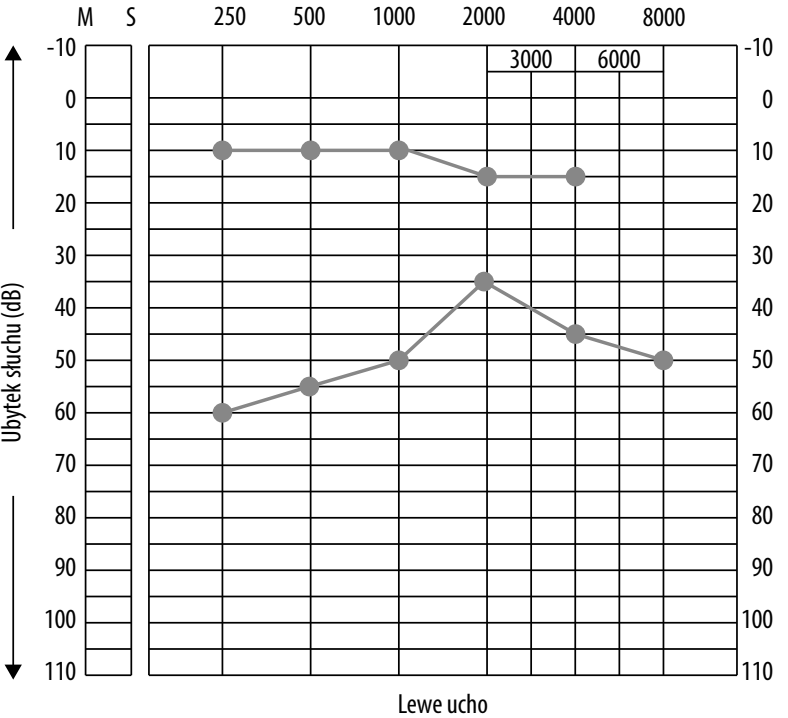

Rycina 2. Audiogram Pacjenta A wykonany w miejscu zamieszkania

Figure 2. Patient $A$, audiogram made in a local center 

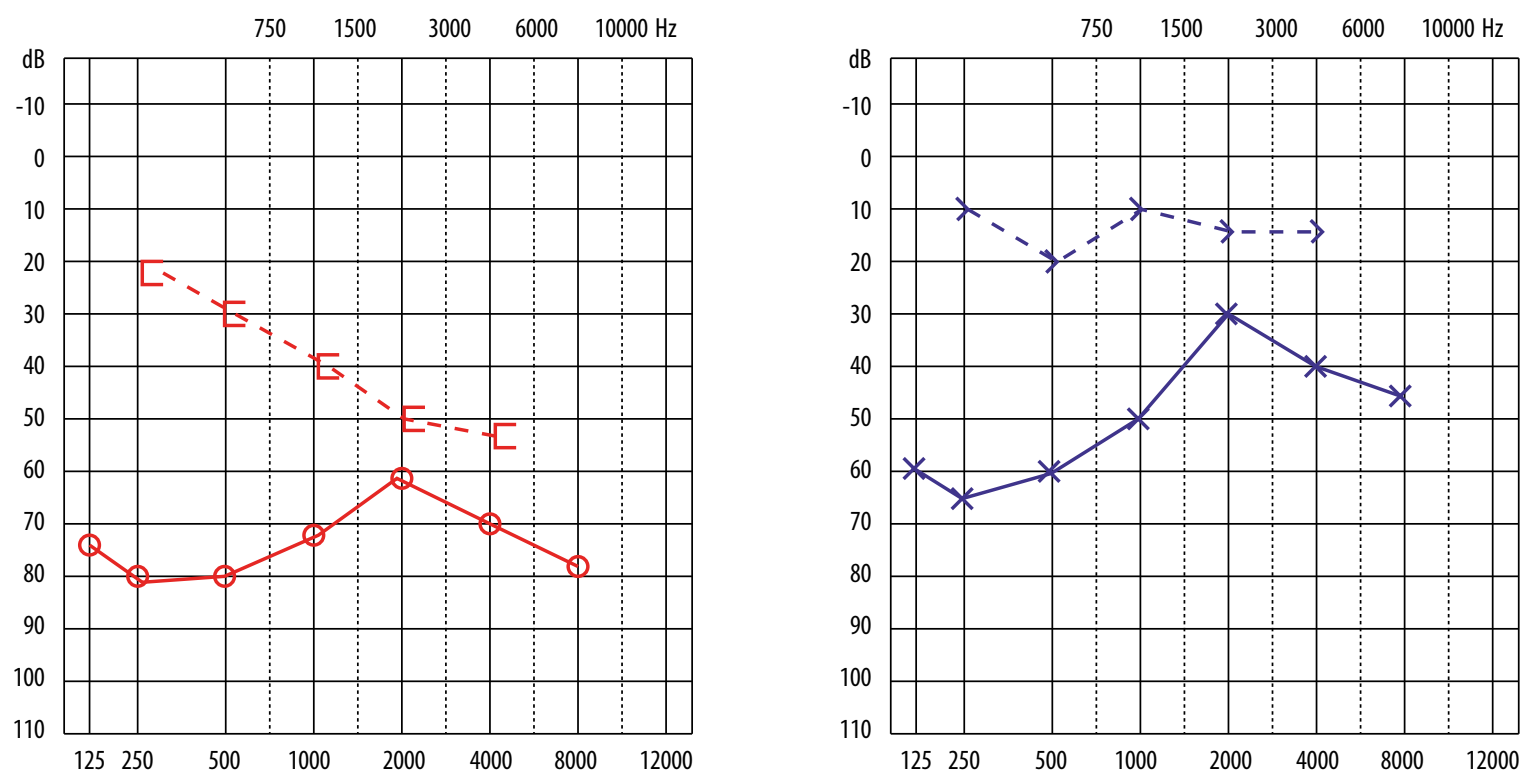

Rycina 3. Audiogram Pacjenta A wykonany w Instytucie Fizjologii i Patologii Słuchu

Figure 3. Patient $A$, audiogram made in the Institute of Physiology and Pathology of Hearing

Wartości progów słyszenia, zarówno dla przewodnictwa powietrznego, jak i kostnego, określone w audiometrii tonalnej (rycina 3) w znacznym stopniu pokrywały się z wynikiem otrzymanym w ośrodku rejonowym pacjenta. Do określenia progu słyszenia przewodnictwa kostnego po stronie prawej wykorzystano metodę zagłuszania Mitkiewicz-Szreniawskiej [12].

W audiometrii impedancyjnej obustronnie uzyskano tympanogramy typu A. Do ich oceny wykorzystano klasyfikację Jergera i Lidena [13,14]. Obustronnie nie zarejestrowano odruchów z mięśnia strzemiączkowego (stymulacja ipsi- i kontrlateralna).
Kolejnym badaniem wykonanym u mężczyzny była audiometria mowy, której wynik zobrazowany został na rycinie 4. Do wyznaczenia progu dyskryminacji użyto Polskiego Testu Słownego opracowanego w roku 2011 w Poznaniu, który jest modyfikacją testu NLA93 [15,16]. $\mathrm{Z}$ uwagi na wynik próby Rinnego badanie wykonano z zagłuszaniem ucha przeciwnego szumem szerokopasmowym, zgodnie z zasadami maskowania zawartymi w normie PN-EN ISO 8252-3: 2012 [17]. W obojgu uszach pacjent nie zidentyfikował $100 \%$ podawanych $\mathrm{w}$ teście jednostek słownych. W uchu lewym osiągną 95-proc. zrozumiałość mowy, natomiast w uchu prawym 5-proc.

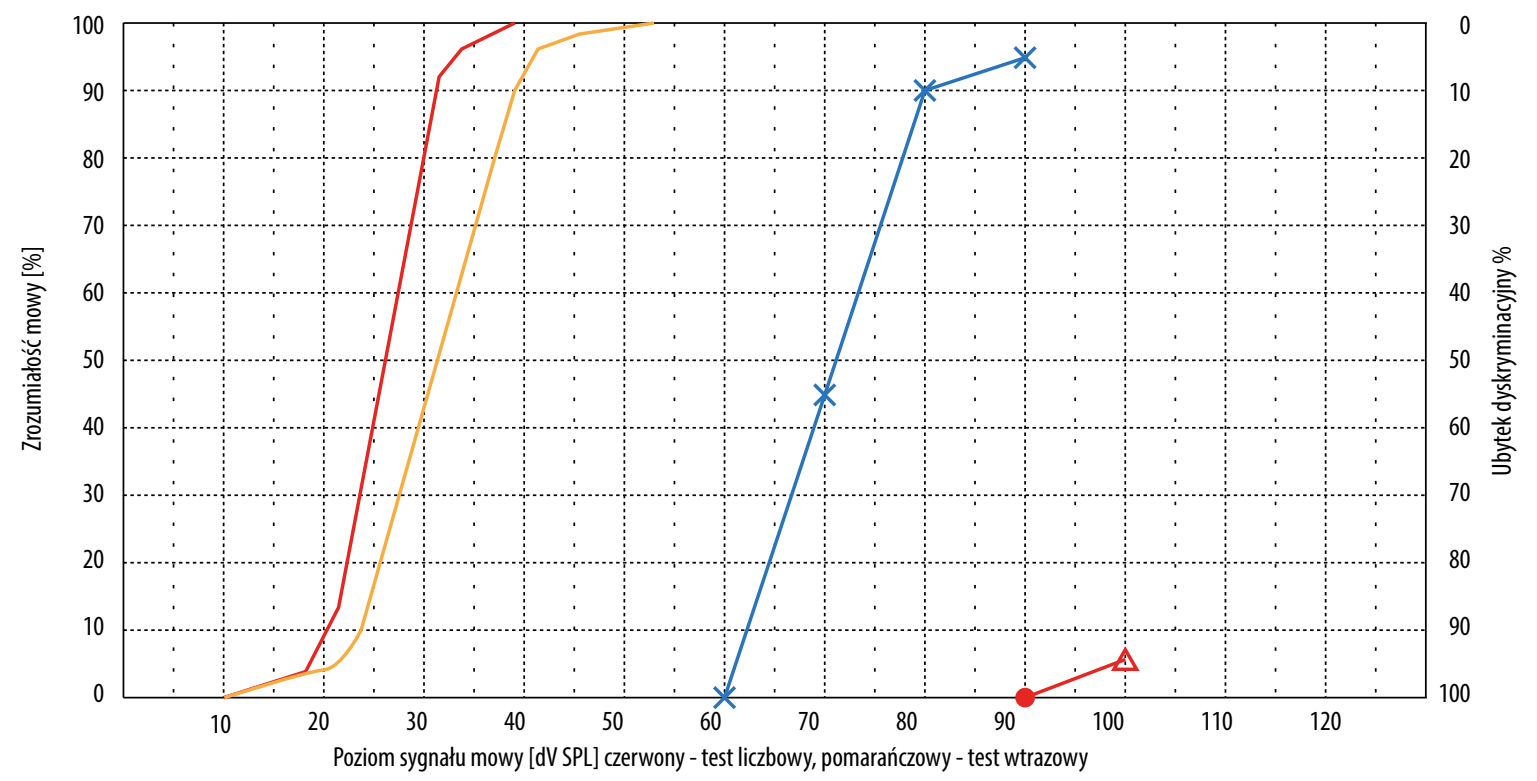

Rycina 4. Audiogram słowny Pacjenta A wykonany w Instytucie Fizjologii i Patologii Słuchu

Figure 4. Patient A, word audiogram made in the Institute of Physiology and Pathology of Hearing 


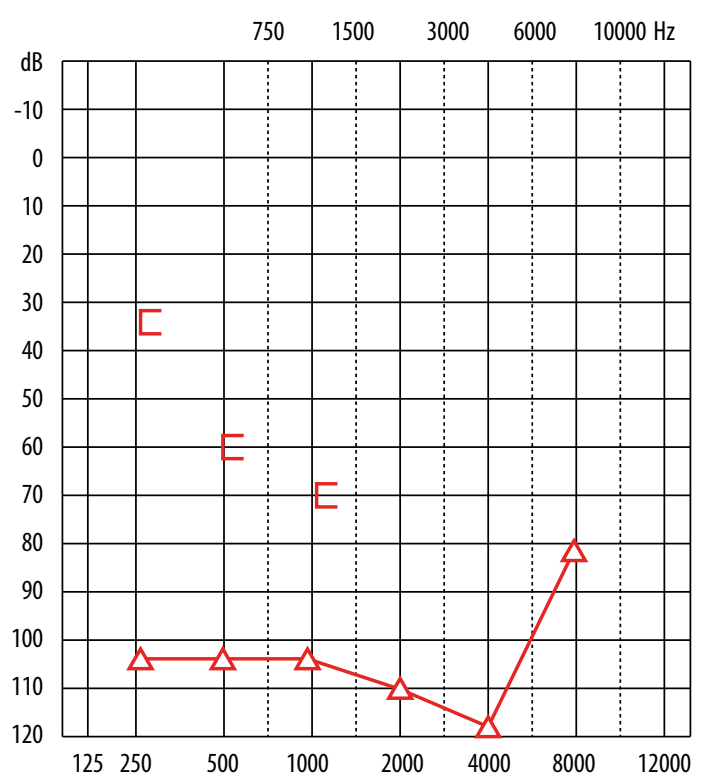

Rycina 5. Audiogram Pacjenta A wykonany w Instytucie Fizjologii i Patologii Słuchu wykreślony z wykorzystaniem metody efektywnego maskowania

Figure 5. Patient $A$, audiogram made in the Institute of Physiology and Pathology of Hearing using the effective masking methods

Ze względu na wykluczające się wyniki badań subiektywnych określono raz jeszcze próg słyszenia dla przewodnictwa powietrznego i kostnego w uchu prawym $\mathrm{z}$ wykorzystaniem metody efektywnego maskowania [4,5]. Jak widać na rycinie 5, nastąpiło znaczne podwyższenie wartości progu słyszenia dla obu przewodnictw. W czasie wyznaczania progu przewodnictwa kostnego pacjent jednocześnie słyszał i odczuwał wibracje dźwięków prezentowanych poprzez przetwornik kostny.

U Pacjentki B w audiometrii tonalnej określono progi słyszenia dla przewodnictwa powietrznego w paśmie częstotliwości od $0,125 \mathrm{kHz}$ do $20 \mathrm{kHz}$ i przewodnictwa kostnego od $0,25 \mathrm{kHz}$ do $4 \mathrm{kHz}$. Do oceny ilościowej badania progowego wykorzystano klasyfikację BIAP [18]. Stwierdzono, że obustronnie słuch jest prawidłowy.

W audiometrii mowy kobieta osiągnęła próg rozumienia mowy, a krzywe artykulacyjne przebiegały w pobliżu krzywej normatywnej [15].

Rejestracji sygnałów emisji produktów zniekształceń nieliniowych dokonano w paśmie częstotliwości od $0,5 \mathrm{kHz}$ do $16 \mathrm{kHz}$. Wszystkie otrzymane wartości odpowiedzi DPOAE przewyższały szum o $6 \mathrm{~dB}$, co wskazywało na obecność emisji otoakustycznej w obojgu uszach [19].

Następnie wykonano diagnostykę różnicową potencjałów wywołanych pnia mózgu dla bodźca typu trzask o intensywności 90 dB HL i częstości powtarzania bodźca 37/s i 11/s. Morfologia zapisu ABR była prawidłowa, a parametry odpowiedzi nie wykazały zwolnienia przewodnictwa neuronalnego w nerwie słuchowym [20].

W audiometrii impedancyjnej obustronnie uzyskano tympanogramy typu A $[13,14]$. Podczas stymulacji ipsilateralnej dla badanych częstotliwości obustronnie zarejestrowano odruchy z mięśnia strzemiączkowego na poziomie $80 \mathrm{~dB}$ HL, a dla stymulacji kontrlateralnej - na poziomie $85 \mathrm{~dB}$ HL.

Następnie sprawdzono drożność trąbek słuchowych, wykorzystując w tym celu test Williams [21]. Z uwagi na poziom trudności tego testu, badanie wykonano dwukrotnie. Uzyskane wyniki były powtarzalne. Na rycinie 6 . zobrazowano wynik testu ETF. Analiza krzywych tympanometrycznych pokazała, że kobieta ma po obu stronach częściowo niedrożne trąbki słuchowe. Krzywe tympanometryczne nie przesuwały się na wykresie w odpowiednim kierunku ciśnień dodatnich bądź ujemnych (po przełknięciu w kierunku ciśnień ujemnych, po wdmuchaniu powietrza w kierunku dodatnich) [22,23]. Jak wynika z ryciny, w uchu lewym (A) po przełknięciu nie nastąpiło przesunięcie szczytu tympanogramu w kierunku ciśnień ujemnych, natomiast w uchu prawym (B) po przełknięciu tympanogram przesunął się w kierunku ciśnień dodatnich, a po wdmuchaniu powietrza w kierunku ujemnych.

\section{Dyskusja}

Celem pracy było pokazanie, jak istotne jest stosowanie zasady cross-check w praktyce audiologicznej. Potwierdzono, iż w czasie diagnostyki ważne jest nie tylko stosowanie odpowiednich procedur badawczych czy właściwa współpraca ze strony pacjenta, lecz także weryfikowanie otrzymywanych badań za pomocą innych testów obiektywnych i subiektywnych.

U Pacjenta A wynik próby Rinnego dla ucha prawego nie korelował $\mathrm{z}$ wyznaczonym audiogramem po tej stronie. Potwierdzenie tego, że wykreślony początkowo próg słyszenia w uchu prawym nie oddaje faktycznego stanu słuchu tego ucha, uzyskano dzięki wynikom otrzymanym w audiometrii słownej. Wyznaczono zatem ponownie próg słyszenia z wykorzystaniem innych metod zagłuszania, co pozwoliło na ustalenie właściwego progu słyszenia w uchu prawym. Okazało się bowiem, iż nastąpił przesłuch pomiędzy przewodnictwem powietrznym ucha badanego i przewodnictwem kostnym ucha niebadanego. Natomiast w czasie określania progu słyszenia przewodnictwa kostnego z wykorzystaniem metody maskowania Mitkiewicz-Szreniawskiej doszło do niedomaskowania, z uwagi na brak możliwości oszacowania poziomu natężenia szumu potrzebnego do wyłączenia ucha niebadanego.

W przypadku Pacjentki B standardowo wykonane badania nie wykazywały przyczyny zatykania uszu, a tym samym odczuwania szumów usznych. Dopiero dzięki testowi Williams stwierdzono dysfunkcyjność trąbek słuchowych, których nieprawidłowa praca przyczyniała się do pojawiania się wspomnianych objawów.

Analiza wyników i informacji dotyczących leczenia obojga pacjentów w innych poradniach otolaryngologicznych nie wskazywała na zastosowanie tam zasady cross-check $\mathrm{w}$ procesie diagnostycznym. Jednakże $\mathrm{z}$ uwagi na brak wglądu w całą dokumentację nie można wykluczyć, że próba weryfikacji wykonywanych badań była podejmowana, a błędne diagnozy powstały na skutek stosowania niewłaściwych procedur badawczych. 
A

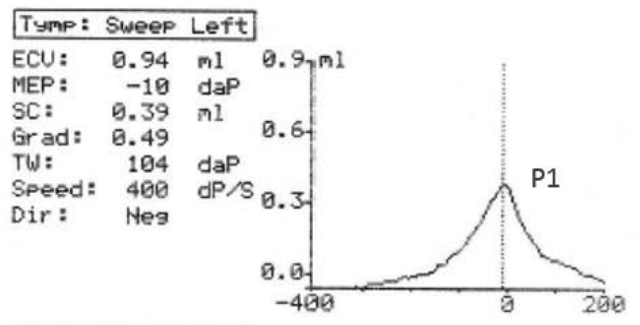

TYMP: ETF-I Left:

ECU1: $0.77 \mathrm{ml} 0.9 \mathrm{ml}$

ECU2: $9.94 \mathrm{ml}$

MEP 1: -10 daP

MEP2:

MEPd:

Dir:

10

Neg

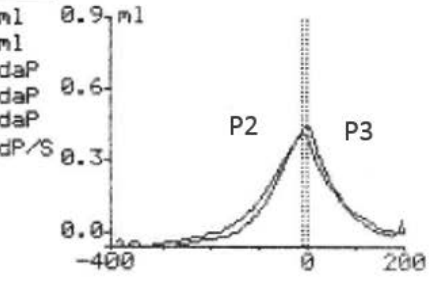

B

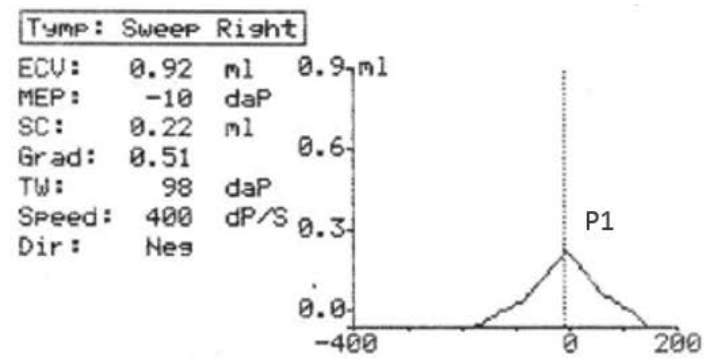

Tymp: ETF-I Right:

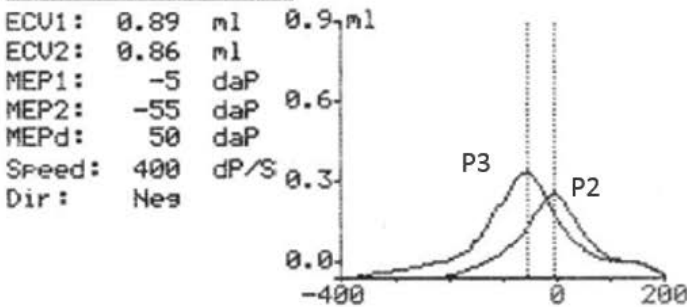

Rycina 6. Wynik testu Williams (testu drożności trąbek słuchowych): A - ucho lewe, B - ucho prawe

P1 - standardowo wykonywany tympanogram bez obciążeń trąbki słuchowej; P2 - tympanogram po przełknięciu śliny przy jednoczesnym zatkaniu nosa; P3 - tympanogram po wykonaniu próby Valsalvy (wdmuchanie powietrza do jam bębenkowych przy jednoczesnym zatkaniu nosa)

Figure 6. Results of the Eustachian Tube Function Test: A - left ear, B - right ear

P1 - tympanogram made in a standard way with no pressure on the Eustachian tube; P2 - tympanogram after swallowing with closed nose; P3 - tympanogram after the Valsalva maneuver (blowing air into a tympanic cavity with closed nose)

\section{Podsumowanie}

W literaturze przedmiotu często podkreślana jest istotność stosowania zasady cross-check w diagnostyce narządu słuchu, dzięki czemu wzrasta jej dokładność.
Każde $\mathrm{z}$ wykonywanych badań słuchu ma ogromne znaczenie w procesie diagnostycznym. Nie należy jednak zapominać o ograniczeniach niektórych metod badawczych. Możliwość potwierdzenia otrzymanych wyników poprzez wykonanie kolejnych testów powoduje znaczne skrócenie czasu diagnozowania zaburzeń słuchu i przyspiesza rozpoczęcie właściwego leczenia czy rehabilitacji.

\section{Piśmiennictwo:}

1. Jerger JF, Hajes D. The cross-check principle in pediatric audiometry. Arch Otolarynol, 1976; 102: 614-20.

2. Turner RG. Double checking the cross-check principle. J Am Acad Audiol, 2003; 14(5): 269-77.

3. Hall JW. Crosscheck principle in pediatric audiology today: A 40-year perspective. J Audiol Otol, 2016; 20(2): 59-67.

4. Furman A. Metody subiektywne badania słuchu. W: Hojan E, red. Protetyka słuchu. Poznań: UAM Wydawnictwo Naukowe; 2014, s.153-210.

5. Piłka E, Piotrowska A. Rola badań audiometrycznych w procesie dopasowania protez słuchowych. W: Dobrucki A, red. Współczesne technologie elektronicznego wspomagania słyszenia osób niedosłyszących. Wrocław: Komitet Akustyki Polskiej Akademii Nauk, Polska Sekcja Audio Engineering Society; 2016, s. 27-45.

6. Lachowska M, Morawski K, Delgado RE, Niemczyk K. Postępy w audiologii. Słuchowe potencjały wywołane stanu ustalonego. Otorynolaryngologia, 2009; 8(1): 1-7.

7. Swanepoel D, Steyn K. Short report: Establishing normal hearing for infants with the auditory steady-state response. S Afr J Commun Disord, 2005; 52: 36-39.

8. Stapells DR, Herdman AT, Small SA, Dimitrijevic A, Hatton J. Current status of the auditory steady-state responses for estimating an infant's audiogram. A Sound Foundation Through Early Amplification, 2004; s. 43-59.

9. Piłka E, Piotrowska A. Próby stroikowe w codziennej praktyce audiologicznej. Now Audiofonol, 2014; 3(1): 57-61.

10. Shehy JL, Gardner G, Hambley WM. Tuning fork tests in modern otology. Arch Otolaryngol, 1971; 94: 132-38.

11. Kochanek K. Zastosowanie słuchowych potencjałów wywołanych pnia mózgu w diagnostyce zaburzeń słuchu u małych dzieci. Audiofonologia, 1999; 14: 51-56.

12. Pruszewicz A, Obrębowski A, red. Audiologia kliniczna. Zarys. Poznań: Wydawnictwo Naukowe Uniwersytetu Medycznego im. Karola Marcinkowskiego; 2010.

13. Jerger J. Clinical experience with impedance audiometry. Arch Otolaryngol, 1970; 92: 311-24.

14. Liden G, Harford E, Hallen O. Automatic tympanometry in clinical practice. Audiology, 1974; 13: 126-39.

15. Demenko G, Pruszewicz A, Wojnowski W. Audiometria mowy. W: Pruszewicz A, Obrębowski A, red. Audiologia kliniczna. Zarys. Poznań: Wydawnictwo Naukowe Uniwersytetu Medycznego im. Karola Marcinkowskiego; 2010, s. 226-61.

16. Piłka E. Testy słowne dostępne i wykorzystane w Polsce $\mathrm{w}$ audiometrii mowy - rys historyczny. Now Audiofonol, 2015; 4(4): 67-74. 
17. PN-EN ISO 8253-3:2012 (wersja angielska) Akustyka - Metodyka pomiarów audiometrycznych - Część 3: Audiometria słowna (zastąpiła wersję polską PN-EN ISO 8253-3:2005)

18. http://www.biap.org/en/recommandation/recommendations-pdf/ct-02-classification -des-deficiences-auditives-1

19. Robinette MS, Glattke TJ. Otoacoustic emissions: clinical applications. New York: Thieme Medical Publishers, Inc; 2007.

20. Kochanek K, Śliwa L. Metody obiektywne badania słuchu. W: Hojan E, red. Protetyka słuchu. Poznań: UAM Wydawnictwo Naukowe; 2014, s. 211-48
21. Williams PS. A tympanometric pressure swallow test for assessment of Eustachian tube function. Ann Otol, 1975; 84: 339-43.

22. Piłka E, Dobrzyński P. Testy oceniające drożność trąbki słuchowej w codziennej praktyce audiologicznej. Now Audiofonol, 2015; 4(1): 67-71.

23. Biswas A. Eustachian tube function test: a new dimension in the management of CSOM. Indian J Otolaryngol Head Neck Surg, 1999; 51(2): 14-22. 